\title{
Transient Myopericarditis Following Vaccination for COVID-19
}

\author{
Jashan Gill a, b, c, Arvin Junn P. Mallaria, b, Farah Zahra ${ }^{\mathrm{b}}$
}

\begin{abstract}
Clinical trials of the messenger ribonucleic acid (mRNA)-1273 vaccine developed by Moderna proved excellent safety and efficacy for severe acute respiratory syndrome coronavirus 2 (SARS-CoV-2) prevention. However, the Centers for Disease Control and Prevention (CDC) has been investigating cases of myocarditis and pericarditis reported in the Vaccine Adverse Event Reporting System (VAERS) database. Currently, the CDC is reporting rates of 40.6 cases per million after second doses of mRNA vaccines administered to males 30 years or younger. Notably, the initial vaccine trials consisted of a limited number of adolescents and young adults; therefore, they were likely not powered to detect this rare potential side effect. We present a case of transient myopericarditis occurring in a young and healthy patient within $48 \mathrm{~h}$ of his second vaccination dose. Although a definitive causal relationship has yet to be determined, we came to this correlation because of the temporal association seen in our patient, secondary to the second dose of vaccination. Furthermore, we also suspect an autoimmune mechanism as the cause of cardiac injury, augmented by the increased vaccine reactogenicity seen in younger patients.
\end{abstract}

Keywords: COVID-19; Perimyocarditis; VAERS; Myocarditis

\section{Introduction}

The World Health Organization declared the novel virus, severe acute respiratory syndrome coronavirus 2 (SARS-CoV-2), as a global pandemic on March 11, 2020 [1], after its emergence in Wuhan, China, in December 2019 [2]. The clinical manifestation of this highly transmissible ribonucleic acid (RNA) virus is coronavirus disease 2019 (COVID-19), presenting with a wide range of respiratory symptoms [3]. Moreover, cardiovascular manifestations of COVID-19 have also been identified, such as acute

Manuscript submitted December 6, 2021, accepted January 25, 2021

Published online February 16, 2022

aDepartment of Medicine, Rosalind Franklin University of Medicine and Science, North Chicago, IL, USA

${ }^{b}$ Department of Medicine, Northwestern Medicine McHenry Hospital, McHenry, IL, USA

${ }^{\mathrm{c} C o r r e s p o n d i n g ~ A u t h o r: ~ J a s h a n ~ G i l l, ~ D e p a r t m e n t ~ o f ~ M e d i c i n e, ~ R o s a l i n d ~}$ Franklin University, McHenry, IL 60050, USA. Email: jashan.gill@nm.org

doi: https://doi.org/10.14740/jmc3876 coronary syndromes, myocardial injury, thromboembolic phenomenon, and arrhythmias. These are related to direct viral infection and indirect injury resulting from exuberant cytokinemia, endothelial inflammation, and microvascular thrombosis [4].

The binding of the SARS-CoV-2 spike protein to the cellular receptor, angiotensin-converting enzyme 2 (ACE2), mediates cellular entry $[3,5]$. Therefore, antibodies that could bind to the spike protein, particularly at the ACE2 receptor biding domain, could neutralize the virus by preventing its attachment to the host cell [6]. This concept was the foundation for developing vaccines against SARS-CoV-2. In December 2020, the first two messenger ribonucleic acid (mRNA)-based vaccines received emergency use approval for distribution in the USA. These were BNT162b2 developed by Pfizer and mRNA-1273 developed by Moderna, which demonstrated $95 \%$ and $94.1 \%$ protection against SARSCoV-2, respectively [7-9]. Although these vaccines have been proved to have excellent efficacy and safety, there have been reports of various side effects associated with vaccination. Approximately 1,226 cases of myocarditis and pericarditis reported in the Vaccine Adverse Event Reporting System (VAERS) database, primarily occurring in young individuals after receiving their second vaccination dose [10]. This report summarizes a case of transient myopericarditis occurring in a young and healthy male within $48 \mathrm{~h}$ of receiving his second dose of the mRNA-1273, SARS-CoV-2 vaccine.

\section{Case Report}

\section{Investigations}

A 44-year-old male presented with left-sided chest pain radiating to the left arm associated with shortness of breath. He had received his second dose of the mRNA-1273 vaccine 4 days before symptom onset. His chest pain began 2 days postvaccination; it was initially mild but progressively became severe. He denied any recent fevers, upper respiratory tract symptoms, or sick contacts. He did not have any past medical history or take any medications. He was a pack per day smoker but did not drink alcohol or use illicit drugs. Vitals signs and physical exam were within normal limits.

\section{Diagnosis}

Complete blood count and comprehensive metabolic panel 


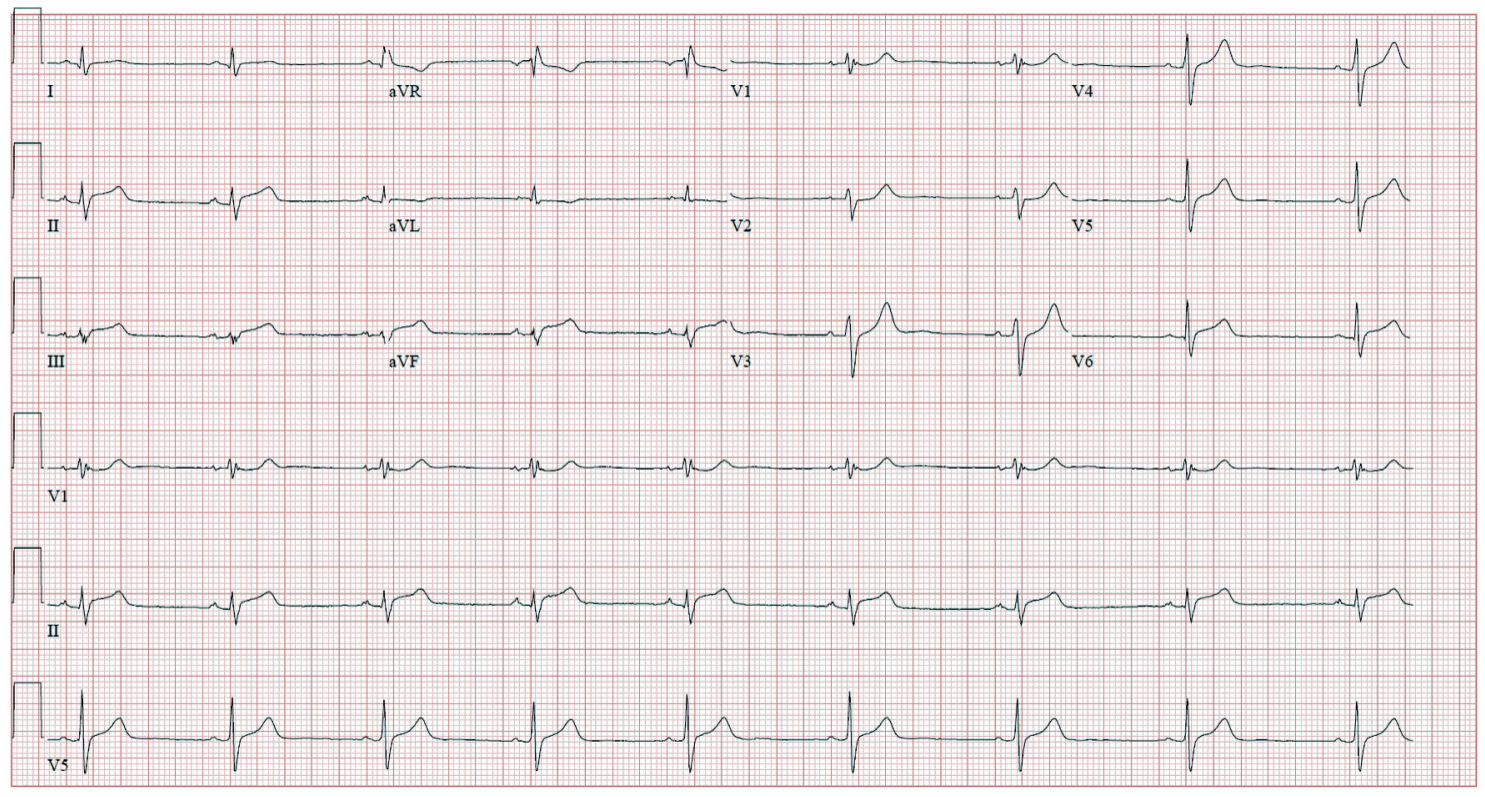

Figure 1. Electrocardiogram showing sinus rhythm with ST-segment elevations in the inferior leads (II, III, and aVF).

were unremarkable. Reverse transcriptase-polymerase chain reaction (RT-PCR) for SARS-CoV-2 was negative. His initial troponin I was $1.40 \mathrm{ng} / \mathrm{mL}$, creatine kinase-myocardial band (CK-MB) was $30.8 \mathrm{ng} / \mathrm{mL}$, erythrocyte sedimentation rate (ESR) was $43 \mathrm{~mm} / \mathrm{h}$, C-reactive protein (CRP) was $3.3 \mathrm{mg} /$ $\mathrm{mL}$, and D-dimer was normal at $100 \mathrm{ng} / \mathrm{mL}$. His electrocardiogram (ECG) showed a normal sinus rhythm with no STsegment changes. He was admitted and received three doses of sublingual nitroglycerin without relief from his chest pain. He was also started on aspirin $81 \mathrm{mg}$ and atorvastatin $40 \mathrm{mg}$ due to concerns of an acute coronary syndrome. Transthoracic echocardiogram showed normal biventricular function, no valvular abnormalities, or pericardial effusion. Troponins were repeated $8 \mathrm{~h}$ after admission and resulted in a significant uptrend to $9.14 \mathrm{mg} / \mathrm{mL}$. ECG was repeated and showed ST-segment elevations in the inferior leads (Fig. 1); therefore, he was started on a heparin infusion. In addition to aspirin, clopidogrel $75 \mathrm{mg}$ was initiated. He underwent left heart catheterization with coronary angiography, which revealed nonobstructive disease. As coronary angiography was nonconclusive cardiac magnetic resonance imaging (MRI) was obtained (Fig. 2), which was consistent with acute myopericarditis, fulfilling the updated Lake Louise criteria. A viral PCR panel was obtained, which was negative for adenovirus, coxsackievirus, Epstein-Barr virus, echovirus, cytomegalovirus, influenza virus, herpes viruses, and parvovirus B19.

\section{Treatment}

After myopericarditis was confirmed, clopidogrel was discontinued. After being admitted for two nights, his chest pain had resolved. His troponin I, ESR, and CRP levels trended down to normal. He was discharged from the hospital on aspirin 81 mg.

\section{Follow-up and outcomes}

At 1-month follow-up the patient had no recurrence of his chest pain. His exercise capacity had returned to his prior baseline. Follow-up transthoracic echocardiography showed normal left ventricular ejection fraction. Aspirin was discontinued at this time.

\section{Discussion}

The rapid development of the mRNA-based vaccines, BNT162b2 (Pfizer) and mRNA-1273 (Moderna) for SARSCoV-2 have been a tremendous achievement in modern medicine. More than 275 million BNT162b2 vaccinations and 180 million mRNA-1273 vaccinations have been administered in the USA [11]. In the initial trials, these vaccines were proved to be safe, with no severe concerns identified. However, there was a high incidence of minor local side effects such as pain, erythema, and swelling at inoculation sites compared with placebo. Transient systemic symptoms such as fever, fatigue, headache, muscle, and joint pain were also more common with vaccination, typically occurring for the first 24 to $48 \mathrm{~h}$ after vaccination $[7,9]$. After approval and distribution of the vaccines in the UK and the USA, several rare cases of anaphylaxis were reported, likely related to the vaccine components, specifically the polyethylene glycol derivatives [12]. Recently, several cases have been published highlighting transient cardiac injury predominantly in adolescents and young adults after SARS-CoV-2 vaccination $[13,14]$. In the initial clinical trials, there were no reported myocarditis or pericarditis events; however, the mean age of the participants was 51 in the mRNA-1273 trial [9], and the median age was 52 in the BNT162b2 trial [7]. This signals that these trials might have lacked adequate power to detect this rare side effect in younger 


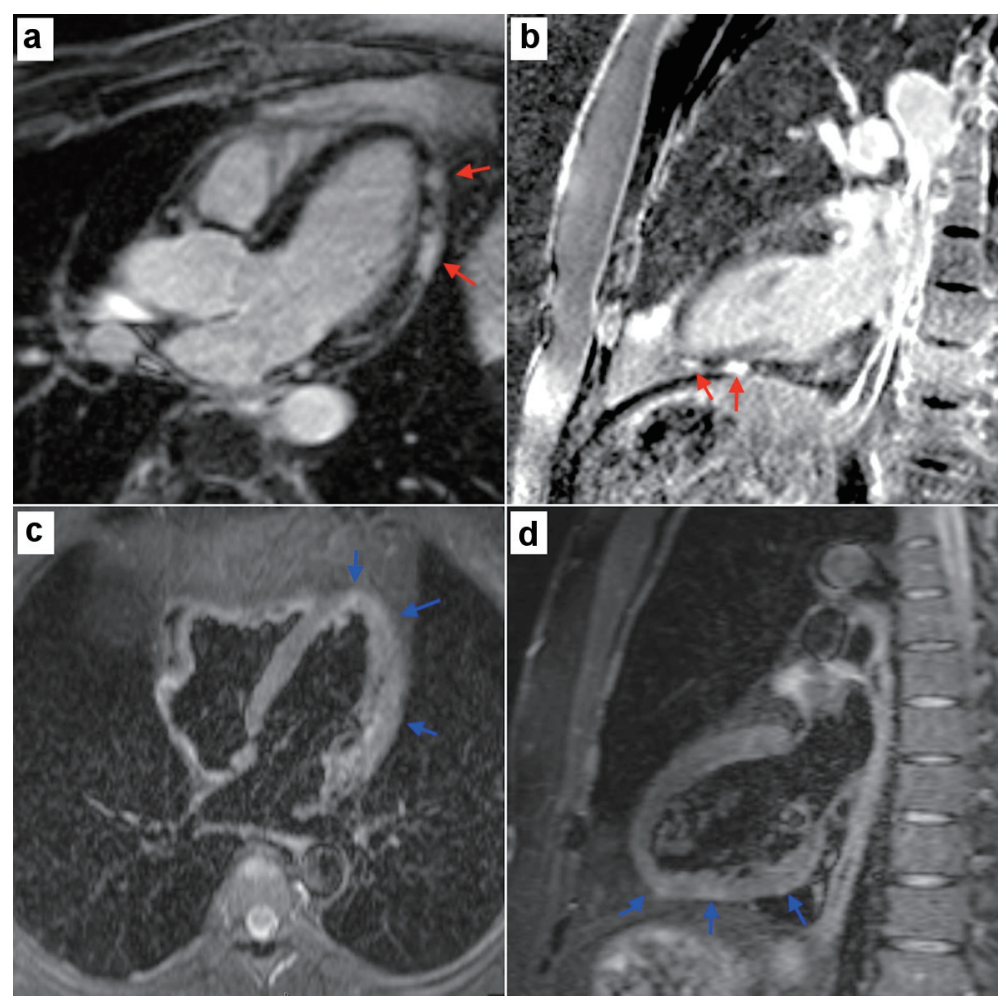

Figure 2. Cardiac magnetic resonance imaging fulfilling the updated Lake Louise criteria. (a) and (b) showed left ventricular foci with early T2 edema (red arrows). (c) and (d) showed subtle delayed T1 enhancement (blue arrows) in the left ventricle. These findings were consistent with mid anterolateral and mid inferolateral wall myopericarditis.

patients. The cardiac injury occurred in our patient within 48 $h$ of inoculation with the second dose of the mRNA-1273 vaccine, consistent with other published cases. No other causative factors were identified. Therefore, given the temporal association with the time of vaccination and symptom onset, we suggest that the transient cardiac injury in our patient was an adverse reaction to his recent vaccination. Moreover, COVID-19 is also a known cause of myocarditis [15], which was ruled out in our patient with a negative SARS-CoV-2 RT-PCR. A viral panel was also obtained to rule out other infectious causes of myopericarditis. Regarding diagnosis and management, monitoring cardiac myocyte injury trends with troponin I, ESR, and CRP were beneficial to track clinical improvement and resolution. Our case also demonstrates the utility of cardiac MRI in the diagnosis of myopericarditis in patients with a high clinical suspicion for postvaccination myopericarditis. Utilizing the 2018 Lake Louise criteria, cardiac MRI has a sensitivity of $87.5 \%$ and a specificity of $96.2 \%$ in detecting myocarditis [16, 17]. The disease course was mild in our patient, and symptoms were resolved with conservative management with aspirin.

Postimmunization myopericarditis has been correlated with other vaccinations [18], with the most substantial evidence for the smallpox vaccine as a cause [19]. In cases of postvaccination myopericarditis with the smallpox vaccine, reports have shown a transient and subclinical course detected by elevated troponin I levels [20], similar to our patient after SARS-CoV-2 vaccination. The hypothesized etiology of cardiac injury after vaccination would be an autoimmune phenom- enon involving molecular mimicry resulting in cross-reactivity between the spike protein of SARS-CoV-2 and self antigens [21]. Vaccine-associated autoimmunity associated with crossreactivity between vaccinal and self antigen, or the immunestimulatory effects of vaccine adjuvant has been previously described [22]. Furthermore, greater systemic reactogenicity has been identified in younger patients after the second vaccine dose, possibly correlating with a higher burden of immunological side effects $[21,23]$. Hence, this appears to be the most likely mechanism of cardiac injury in these patients.

\section{Conclusions}

In unison with recently reported cases, we hypothesize our patient's transient myopericarditis was associated with his recent mRNA-1273 vaccination due to the temporal relationship. However, we recognize that substantial evidence is needed to determine a genuine causal relationship between SARS-CoV-2 vaccination and cardiac injury. Moreover, vaccinations have proven to be lifesaving, with the benefits of the SARS-CoV-2 vaccinations far outweighing the rare risk of myopericarditis, given that COVID-19 in itself likely possesses a higher incidence of myocarditis compared to vaccination. Nevertheless, as the younger populations undergo vaccination, clinicians should be aware of this potential association and transient disease course. All cases should be promptly reported to the VAERS database. 


\section{Learning points}

Learning points from this case report include: 1) Physicians should consider myopericarditis when evaluating adolescents and young adults who present with chest pain after recent SARS-CoV-2 vaccination; 2) Troponin I and CRP are valuable in tracking the disease process. Furthermore, cardiac MRI is an invaluable tool in determining the presence of cardiac injury, utilizing the updated Lake Louise criteria; 3) A conservative treatment approach should be taken in these patients as most cases are transient and without significant sequelae.

\section{Acknowledgments}

None to declare.

\section{Financial Disclosure}

No financial disclosures or funding sources to declare.

\section{Conflict of Interest}

All authors declare that there is no conflict of interest.

\section{Informed Consent}

Informed consent was obtained from the patient presented above for the presentation of this case report and the utilization of labs and imaging.

\section{Author Contributions}

$\mathrm{JG}, \mathrm{AM}$, and FZ all contributed to drafting and revising this manuscript. All authors approve the final draft for submission. All authors agree to be accountable for all aspects of the work.

\section{Data Availability}

The authors declare that data supporting the findings of this study are available within the article.

\section{References}

1. WHO Director-General's opening remarks at the media briefing on COVID-19. March 11, 2020. Available at: https://www.who.int/director-general/speeches/detail/whodirector-general-s-opening-remarks-at-the-media-briefingon-covid-19---11-march-2020. Accessed June 12, 2021.

2. Wu JT, Leung K, Leung GM. Nowcasting and forecasting the potential domestic and international spread of the 2019-nCoV outbreak originating in Wuhan, China: a modelling study. Lancet. 2020;395(10225):689-697.

3. V'Kovski P, Kratzel A, Steiner S, Stalder H, Thiel V. Coronavirus biology and replication: implications for SARSCoV-2. Nat Rev Microbiol. 2021;19(3):155-170.

4. Giustino G, Pinney SP, Lala A, Reddy VY, JohnstonCox HA, Mechanick JI, Halperin JL, et al. Coronavirus and cardiovascular disease, myocardial injury, and arrhythmia: JACC focus seminar. J Am Coll Cardiol. 2020;76(17):2011-2023.

5. Hu B, Guo H, Zhou P, Shi ZL. Characteristics of SARSCoV-2 and COVID-19. Nat Rev Microbiol. 2021; 19(3):141-154.

6. Krammer F. SARS-CoV-2 vaccines in development. Nature. 2020;586(7830):516-527.

7. Polack FP, Thomas SJ, Kitchin N, Absalon J, Gurtman A, Lockhart S, Perez JL, et al. Safety and efficacy of the BNT162b2 mRNA COVID-19 vaccine. N Engl J Med. 2020;383(27):2603-2615.

8. Jackson LA, Anderson EJ, Rouphael NG, Roberts PC, Makhene M, Coler RN, McCullough MP, et al. An mRNA vaccine against SARS-CoV-2 - preliminary report. N Engl J Med. 2020;383(20):1920-1931.

9. Baden LR, El Sahly HM, Essink B, Kotloff K, Frey S, Novak R, Diemert D, et al. Efficacy and safety of the mRNA-1273 SARS-CoV-2 vaccine. N Engl J Med. 2021; 384(5):403-416.

10. Gargano JW, Wallace M, Hadler SC, Langley G, Su JR, Oster ME, Broder KR, et al. Use of mRNA COVID-19 vaccine after reports of myocarditis among vaccine recipients: update from the advisory committee on immunization practices - United States, June 2021. MMWR Morb Mortal Wkly Rep. 2021;70(27):977-982.

11. CDC COVID Data Tracker. Available at: https://covid. cdc.gov/covid-data-tracker/\#vaccinations. Accessed June 12, 2021.

12. Castells MC, Phillips EJ. Maintaining safety with SARSCoV-2 vaccines. N Engl J Med. 2021;384(7):643-649.

13. Marshall M, Ferguson ID, Lewis P, Jaggi P, Gagliardo C, Collins JS, Shaughnessy R, et al. Symptomatic acute myocarditis in 7 adolescents after Pfizer-BioNTech COVID-19 vaccination. Pediatrics. 2021;148(3):e2021052478.

14. Montgomery J, Ryan M, Engler R, Hoffman D, McClenathan B, Collins L, Loran D, et al. Myocarditis following immunization with mRNA COVID-19 vaccines in members of the US military. JAMA Cardiol. 2021;6(10):12021206.

15. Kawakami R, Sakamoto A, Kawai K, Gianatti A, Pellegrini D, Nasr A, Kutys B, et al. Pathological evidence for SARS-CoV-2 as a cause of myocarditis: JACC review topic of the week. J Am Coll Cardiol. 2021;77(3):314325.

16. Ferreira VM, Schulz-Menger J, Holmvang G, Kramer CM, Carbone I, Sechtem U, Kindermann I, et al. Cardiovascular magnetic resonance in nonischemic myocardial inflammation: expert recommendations. J Am Coll Cardiol. 2018;72(24):3158-3176.

17. Luetkens JA, Faron A, Isaak A, Dabir D, Kuetting D, Feisst A, Schmeel FC, et al. Comparison of original and 
2018 lake louise criteria for diagnosis of acute myocarditis: results of a validation cohort. Radiol Cardiothorac Imaging. 2019;1(3): e190010.

18. Mei R, Raschi E, Forcesi E, Diemberger I, De Ponti F, Poluzzi E. Myocarditis and pericarditis after immunization: Gaining insights through the Vaccine Adverse Event Reporting System. Int J Cardiol. 2018;273:183-186.

19. Cassimatis DC, Atwood JE, Engler RM, Linz PE, Grabenstein JD, Vernalis MN. Smallpox vaccination and myopericarditis: a clinical review. J Am Coll Cardiol. 2004;43(9):1503-1510.

20. Faix DJ, Gordon DM, Perry LN, Raymond-Loher I, Tati N, Lin G, DiPietro G, et al. Prospective safety surveil- lance study of ACAM2000 smallpox vaccine in deploying military personnel. Vaccine. 2020;38(46):7323-7330.

21. Talotta R. Do COVID-19 RNA-based vaccines put at risk of immune-mediated diseases? In reply to "potential antigenic cross-reactivity between SARS-CoV-2 and human tissue with a possible link to an increase in autoimmune diseases". Clin Immunol. 2021;224:108665.

22. Goriely S, Goldman M. From tolerance to autoimmunity: is there a risk in early life vaccination? J Comp Pathol. 2007;137(Suppl 1):S57-61.

23. Chapin-Bardales J, Gee J, Myers T. Reactogenicity following receipt of mRNA-based COVID-19 vaccines. JAMA. 2021;325(21):2201-2202. 